Article

\title{
Encompassing Electricity Market Predictions and Weather Forecasts in Power Plan O\&M Strategies
}

\author{
Linda Ponta ${ }^{1, *(1)}$, Luca Oneto ${ }^{2}$, Davide Anguita ${ }^{2}$ and Silvano Cincotti ${ }^{1}$ \\ 1 DIME - University of Genova, Via Opera Pia 15, I-16145 Genova, Italy; linda.ponta@unige.it, \\ silvano.cincotti@unige.it \\ 2 DIBRIS - University of Genova, Via Opera Pia 13, I-16145 Genova, Italy; luca.oneto@unige.it, \\ davide.anguita@unige.it \\ * Correspondence: linda.ponta@unige.it; Tel.: +39-010-353-2029
}

\begin{abstract}
The paper deals with the problem of choosing the best O\&M strategy for wind power plants. Current maintenance theory considers just production opportunities and minimizes the maintenance costs, but with the liberalization of the electricity market also the electricity price has become an important variable to take into account in the O\&M scheduling. Another important variables that is often neglected by the existing maintenance theory is the weather condition. This paper proposes a new strategy that takes into account the electricity price and weather conditions, improves the expected profit of the systems, and reduce the overall maintenance and logistic costs. The maintenance schedule is formalized as an optimization problem where the discounted cumulative profit of a wind generation portfolio in a fixed-time horizon (e.g. two years ahead), subject to the technologically-derived maintenance time constraints is optimized. Both the theoretical and computational aspects of the proposed O\&M strategy are discussed. Results show that taking into account market and weather opportunities in the design of the maintenance strategy, it is possible to achieve a more complete scheduling for a given set of wind power plants.
\end{abstract}

Keywords: Electricity markets; Proactive maintenance; Wind energy systems.

\section{Introduction}

The deregulation of electricity in Europe started in the early 1990s moving from monopolistic state-owned suppliers to competitive electricity market. This migration started with "The energy Act" in Norway in the 1990, followed by the European Directive 96/92/CE, then by the Law 54/97 27 November 1997 in Spain, and finally by the D.L. n.79/99 16 March 1999 in Italy [1]. Generally speaking, the new framework is formed by several market sessions to clear the market, to guarantee production plan feasibility and to secure transmission. Over almost a century, electrical energy was traded between vertically integrated utilities and electricity consumers. Even until today, this kind of trading is still being implemented in some parts of the world. At one point, the economists have suggested that the prices would be lower and that the economy as a whole would benefit if the supply of electricity becomes the object of market discipline [2]. Since then, some countries have designed several market structures that can be adopted for liberalization of electricity market. For example, the Italian wholesale electricity market started its operations in April 2004 but became an Exchange only in 2005, registering an increasing in traded volumes from 73 TWh in 2004 to 207 TWh in 2013. The liberalization process brought about the replacement of old administrative procedures with market mechanisms more suited to the new framework for power trade. Italy is divided in geographic zones with different zonal prices subject to the transmission of network structural constraints. Like the financial market [3-6], also the energy market can be simulated in a lot of ways [7-12].

In the last years a number of policies aiming at boosting renewable energy have been developed. The forthcoming reduction of these incentives will lead to a large presence of bids for renewable energy power plants in the day-ahead market. Day-ahead markets are currently implemented in several power exchanges around the world, and mainly consist on a single daily auction, while some markets 
additionally incorporate a continuous trading platform for day-ahead transactions. These auctions receive the day-ahead Gencos and demand hourly bids, determining the hourly schedules and market prices.

Moreover, energy conversion and efficiency improvement have become a worldwide priority to secure an energy supply and address the challenges of climate change, greenhouse gas emission reduction, biodiversity protection, and renewable technology development [13]. Among all renewable energy sources, wind energy has experienced an extensive and worldwide growth in terms of installed capacity [13-16].

Unlike conventional power stations, wind turbines are unmanned, remote power plants that are exposed to highly variable and harsh weather conditions, including calm to severe winds, tropical heat, lightning, arctic cold, hail, and snow. Due to these external variations, wind turbines undergo constantly changing loads, which result in highly variable operational conditions that lead to intense mechanical stress.

Consequently, the efficient operation of installed generating units has acquired an increasing importance and the planning and scheduling of maintenance has become a crucial task both for generation unit availability and operational costs (see [17] for details).

The availability of various resources and spare parts, as well as appropriate skilled personnel, must be considered by the scheduler while minimizing the disruptions caused in production $[18,19]$. From the maintenance scheduling aspect, a wind power generator system is quite similar to a manufacturing system, since the scheduler has to respond quickly to new events in a rapidly changing environment [20]. Nevertheless, it is worth noting that there are a number of differences, like the different operating conditions and the dependence on weather conditions.

The maintenance planning and scheduling in manufacturing and service industry have been widely studied using mathematical models and optimization methods [21-39]. Recently, the technological and economic questions related to reducing operational and maintenance costs of wind energy generating units have received significant attention. The most efficient solution would be to continuously monitor the condition of these systems, so that in case of failure a proactive response, minimizing downtime and maximizing productivity, could be adopted [40-45].

The incentives for renewable energy productions and the specific nature of wind power plants have lead to consider the renewable power as a basic contribution to the GenCos bids and the O\&M as a pure technological strategy.

In these respects, it is worth noting that the classical maintenance methods for wind energy systems can be classified into corrective maintenance, preventive maintenance and proactive maintenance [46-48]:

corrective maintenance is released for scheduling upon the localization of a failure in a generating unit

preventive maintenance (or condition-based maintenance) is triggered by a prognosed failure

proactive maintenance results suitable when the task becomes timely and the retrofitting activities are released by high-level decisions

Generally speaking, the main goal of the classical optimal O\&M is to allocate a maintenance timetable able to maintain high system reliability, reduces total operating costs and extends generator life time, satisfying constraints on the individual generators. The criteria based on economic cost or based on reliability are the most employed for O\&M problem $[49,50]$. The most common economic objective is to minimize the costs of energy production and maintenance, i.e. the total operating cost $[51,52]$. The outage durations are a trade-off between the energy production cost and the maintenance cost. Shorter outage durations lead to higher maintenance costs but reduce the load of expensive generation and possible energy purchases, resulting in lower energy production costs [49].

In order to solve the classical maintenance problem, and thus find feasible solutions to the objecting function in the time interval under examination, the heuristic-based techniques use a 
specialized method that require significant operator input and may even fail [53]. These limitations can be overcome using several meta-heuristic and soft computing approaches, such as genetic algorithms [54,55], simulated annealing (SA) [56,57], evolutionary programming [58], fuzzy logic [52] and their hybrids [52,59-62].

So far, the literature did not take into account market and weather conditions in the maintenance strategy, if we exclude a preliminary conference paper [63]. Nevertheless the price of energy, the wind speed and temperature play an important role in the O\&M. It is worth noting that the maintenance tasks requiring an outer crane can be executed in calm winds only. There might be minimum and maximum values of each weather parameter assigned to every maintenance task, depending on the type of work to be done, as well as the local safety regulations.

In this paper a maintenance scheduling that takes into account market and production opportunities is formalized as a new nonlinear optimization problem. Moreover maintenance is performed in order to ensure most profitable conditions in terms of energy prices and wind environment, rather than only minimizing maintenance costs for a given set of generation plants.

The theoretical and computational aspect employed for the design of the maintenance strategies able to maximize profits are considered. A maintenance schedule that optimizes a discounted cumulative profit of a wind generation portfolio in a fixed-time horizon (e.g. two years ahead) and subject to the technologically-derived maintenance time constraints is modeled. Furthermore, logistics costs are also considered so to evaluate impacts of the location of warehouses.

As a result, the mathematical formulation of the problem is presented together with a procedure for the solution based on computational intelligence techniques. The paper is organized as follows: Section 2 presents the model and the solution method, Section 3 shows the computational experiments and the discussion of results and Section 4 provides the conclusion of the study.

\section{The Model}

In this section, starting from the classical maintenance theory, a model of O\&M scheduling able to incorporate forecasted market prices and weather conditions is presented. The profit-based O\&M problem is formulated as a non linear integer programming problem with boolean constraints. Note that in order to improve the readability of the paper all the symbols are summarized in Tables 1 and 2.

Table 1. Mathematical Symbols.

\begin{tabular}{cl}
\hline Symbol & Description \\
\hline $\mathbb{B}$ & Boolean variable $\mathbb{B}=\{0,1\}=\{$ false, true $\}$ \\
$\mathbb{N}$ & Natural non negative numbers $\mathbb{N}=\{0,1,2, \ldots\}$ \\
$\mathbb{Z}$ & Integer numbers $\mathbb{Z}=\{\ldots,-2,-10,1,2, \ldots\}$ \\
$\mathbb{R}$ & Real numbers \\
$\bar{x}$ & Logical negation (NOT) \\
$\vee$ & Logical disjunction (OR) \\
$\wedge$ & Logical conjunction (AND) \\
\hline
\end{tabular}


Table 2. Parameters notation used in the mathematical model.

\begin{tabular}{|c|c|c|c|}
\hline Symbol & Kind & Element & Description \\
\hline$S$ & $\mathbb{N}$ & - & Number of sites \\
\hline G & $\mathbb{N}^{S}$ & $G_{i S}$ & Number of unit in the site iS \\
\hline$n U$ & $\mathbb{N}$ & - & Number of units \\
\hline$T$ & $\mathbb{N}$ & - & Number of the time periods \\
\hline$P$ & $\mathbb{R}^{T}$ & $P_{t}$ & Energy price at time $t$ \\
\hline$Q$ & $\mathbb{R}^{n U \times T}$ & $Q_{t, i U}$ & Generating capacity of unit $i U$ at time $t$ \\
\hline$T^{\text {last }}$ & $\mathbb{Z}^{n U}$ & $T_{i U}^{\text {last }}$ & Starting time of last maintenance of the unit $i U$ \\
\hline$\Delta T^{\min }$ & $\mathbb{N}^{n U}$ & $\Delta T_{i U}^{\min }$ & Minimum period of working time of unit $i U$ \\
\hline$\Delta T^{\max }$ & $\mathbb{N}^{n U}$ & $\Delta T_{i U}^{\max }$ & Maximum period of working time of unit $i U$ \\
\hline$\Delta T^{\operatorname{man}}$ & $\mathbb{N}^{n U}$ & $\Delta T_{i U}^{\operatorname{man}}$ & Duration of the maintenance for the unit $i U$ \\
\hline$\Delta T$ & $\mathbb{N}^{n U \times ?}$ & $\Delta T_{i U, i K}$ & $\begin{array}{l}\text { Time between the } i K \text { and the } i K+1 \text { maintenance } \\
\text { on the unit } i U \text {. Note that it is not possible to know } \\
\text { a priori how many maintenance we will perform } \\
\text { on the unit } i U\end{array}$ \\
\hline$C^{M}$ & $\mathbb{R}^{n U}$ & $C_{i U}^{M}$ & $\begin{array}{l}\text { Maintenance intervention cost on the unit } i U \text { for } \\
\text { the maintenance }\end{array}$ \\
\hline$C^{L}$ & $\mathbb{R}^{n U \times n U}$ & $C_{i U_{1}, i U_{2}}^{L}$ & $\begin{array}{l}\text { Logistic cost of the team } i T \text { for going from the unit } \\
i U_{1} \text { to the unit } i U_{2} \text {. }\end{array}$ \\
\hline$r$ & $\mathbb{R}$ & - & Discount factor \\
\hline$\beta$ & $\mathbb{B}^{n U \times T}$ & $\beta_{i U, t}$ & $\begin{array}{l}\text { Flags that indicates if the team must perform the } \\
\text { maintenance to the unit } i U \text { at time } t \text { : Optimal O\&M } \\
\text { scheduling }\end{array}$ \\
\hline
\end{tabular}

Let $S$ be the number of sites, $G$ the number of generation units for each site,

$$
n U=\sum_{i S=1}^{S} G_{i S}
$$

the total number of generating units, $T$ the planning horizon. The number of maintenances considered is equal to one as well as the number of the maintenance team. Furthermore, we denote with $P_{t}$ the energy price at time $t$ and $Q_{t, i U}$ the production capacity of generation unit $i U$ at time $t$, respectively. The energy price $P_{t}$ is forecasted on the base of the historical results of the electricity market, whereas the expected production capacity $Q_{t, i U}$ depends on the wind speed at time $t$ and on the technical characteristics of the generating unit $i U$. In particular, the wind distribution in the short time (few days ahead) is modeled using a Navier-Stokes computational system [64], whereas for longer periods the wind forecast is based on statistical models. Moreover, Support Vector Machines (SVMs) are used for statistical forecast based on historical time series [65].

In the presented model, the total costs are divided in two groups, i.e., the maintenance cost and the logistic cost. The maintenance $\operatorname{cost} C^{M}$ depends on the technical parameters of the specific generating unit. The logistic cost $C^{L}$ is related to the sequence of generating units that are in maintenance. Thus, $C_{i U}^{M}: C^{M} \in \mathbb{R}^{n U}$ is the maintenance intervention cost on the unit $i U \in\{1, \ldots, n U\} . C_{i U_{1}, i U_{2}}^{L}$ : $C^{L} \in \mathbb{R}^{n U \times n U}$ represents the logistic cost for going from the unit $i U_{1} \in\{1, \ldots, n U\}$ to the unit $i U_{2} \in\{1, \ldots, n U\}$.

\subsection{Decision Variable}

A set of boolean variables is used as decision variables. In particular $\beta$ is a matrix such that $\beta \in \mathbb{B}^{n U \times T}$ where:

$$
\beta_{i U, t}= \begin{cases}1 & \text { if the generating unit } i U \text { at time } t \text { is in maintained } \\ 0 & \text { otherwise }\end{cases}
$$




\subsection{Objective Function}

Generally speaking, the problem of maintenance scheduling can be written as a multi objective function in order to take into account both time, maintenance and power plant dimensions. The objective function is characterized by forecasted data and different time horizon. This results in a mathematical problem extremely difficult to optimize because of uncertainty in forecasts and of the non linear and integer nature of the problem. Indeed, the forecasts are characterized by different accuracy for different time horizon (i.e. short, medium and long). In order to take into account the different levels of accuracy of forecasted price and weather conditions, we propose to introduce a discount factor $r$ that directly incorporates the fact that in the short-run the forecasting is more accurate than in the long-run. In this work, a fixed (time-invariant) annual discount factor is considered, but it is worth noting that an immediate extension may be to consider a time variant discount factor related to the quality of the market and weather forecasts. Irrespective to a formulation based on either fixed or variable discount rate, a one-dimensional objective function that considers the time, maintenance and power plant dimensions in a single framework is defined. For this purpose, let us suppose that the generation units never stop and that our forecast of the energy price and generating capacity is perfect; therefore, the total profit will be:

$$
\sum_{t=1}^{T} \sum_{i U=1}^{n U} P_{t} Q_{t, i U}
$$

where $P_{t}$ is the energy price at time $t$ and $Q_{t, i U}$ is the energy quantity produced at time $t$ by the generating unit $i U$. Since the units must be maintained, the missed-profit due to the maintenance of the different generating units is computed as:

$$
\sum_{t=1}^{T} \sum_{i U=1}^{n U} \beta_{i U, t} P_{t} Q_{t, i U}
$$

where $\beta_{i U, t}$ is the boolean variable that is equal to one if the generating unit $i U$ is in maintenance at time $t$. Moreover the costs of the maintenance for the different generating units are computed as:

$$
\sum_{t=1}^{T} \sum_{i U=1}^{n U} \beta_{i U, t} \frac{C_{i U}^{M}}{\Delta T_{i U}^{\operatorname{man}}}
$$

where $C_{i U}^{M}$ is the maintenance cost. Finally, the logistic costs to go from one unit to another based on the maintenance scheduling $\beta$ is computed:

$$
\begin{aligned}
& \sum_{t=1}^{T-1} \sum_{i U_{1}=1}^{n U} \sum_{i U_{2}=1, i U_{2} \neq i U_{1}}^{n U}\left[\beta_{i U_{1}, t} \wedge \beta_{i U_{2}, t+\Delta_{t}}\right] C_{i T, i U_{1}, i U_{2}}^{L} \\
& \Delta_{t}=\min _{a \in 1, \ldots, T} a, \quad \text { s.t. } \bigvee_{i U=1}^{n U} \beta_{i U, t+a}=1
\end{aligned}
$$

where $C^{L}$ is the logistic cost. In order to take into account the accuracy of the forecast of the energy price and generating capacity, the discount factor $r$ described above is introduced. Consequently the objective function is 


$$
\begin{aligned}
\max _{\beta} & \sum_{t=1}^{T} e^{-r t}\left[\sum_{t=1}^{T} \sum_{i U=1}^{n U} P_{t} Q_{t, i U}\right. \\
& -\sum_{t=1}^{T} \sum_{i U=1}^{n U} \beta_{i U, t} P_{t} Q_{t, i U} \\
& -\sum_{t=1}^{T} \sum_{i U=1}^{n U} \beta_{i U, t} \frac{C_{i U}^{M}}{\Delta T_{i U}^{\operatorname{man}}} \\
& \left.\sum_{t=1}^{T-1} \sum_{i U_{1}=1}^{n U} \sum_{i U_{2}=1, i U_{2} \neq i U_{1}}^{n U}\left[\beta_{i U_{1}, t} \wedge \beta_{i U_{2}, t+\Delta_{t}}\right] C_{i T, i U_{1}, i U_{2}}^{L}\right] \\
& \Delta_{t}=\min _{a \in 1, \ldots, T} a, \quad \text { s.t. } \bigvee_{i U=1}^{n U} \beta_{i U, t+a}=1
\end{aligned}
$$

\subsection{Constraints}

The optimization problem defined in Eq. (8) is subject to two types of non-linear constraints, i.e., maintenance window constraints and minimum maintenance period.

The former one accounts that there is a minimum $\Delta T_{i U}^{\min }$ and a maximum $\Delta T_{i U}^{\max }$ for the time period between two consecutive operational maintenances. This time period is subject to an a priori expected probability in the rate of failure and is prescribed by the power plant constructor. The time period between the start of the maintenance of the power plant $i U$ is denoted by $\Delta T_{i U, i K}$ and the maintenance window constraint yields

$$
\Delta T_{i U}^{\min } \leq \Delta T_{i U, i K} \leq \Delta T_{i U}^{\max },\left\{\begin{array}{c}
\forall i U \in\{1, \ldots, n U\} \\
\forall i K \in\{1, \ldots, ?\}
\end{array}\right.
$$

where? means that, a priori, it is not possible to know how many times a unit will perform a particular maintenance. It is worth noting that in order to verify this constraints we need some initial conditions of the problem, i.e. the last time that each unit has performed the maintenance. This information is embedded in the vector $T^{\text {last }}$.

The latter constraint considers the finite number of maintenance teams. In particular, assuming a single maintenance and denoting with $\Delta T$ the time interval between two starting maintenances, each time the maintenance must be less then the time interval between two starting maintenances.

Finally we have to ensure that the maintenance time slot for each unit respects the parameters of the $\Delta T^{\text {man }}$.

\subsection{Optimization Methods}

Sections 2.2 and 2.3 define the general mathematical model for a maintenance problem formulated as a non-linear binary integer programming problem with boolean constraints. The objective is to determine the schedule of maintenance in order to maximize discounted profit (see Section 2.2) subject to the constraints described in Section 2.3.

It is worth noting that this problem results extremely difficult to be solved. Indeed, its non-linear integer programming nature together with boolean constraints lets the problem become non-convex. A non-convex optimization problem is any problem where the objective function or one of the constraints is non-convex. Such a problem may have multiple feasible regions and multiple locally optimal points within each region. Generally speaking, it requests a computational time that is exponential in the number of variables and constraints in order to determine if either the non-convex problem is infeasible, the objective function is unbounded or an optimal solution is the global optimum across all feasible 
regions. In addition, this problem has a number of constraints that depends on the particular algorithm employed for the solution. In fact, the number of $\Delta T_{i U, i K}$ in Eq. (10) changes over time, depending on the maintenance scheduling, thus leading to an a priori undetermined number of boolean constraints.

For the solution of non-linear integer programming problems with boolean constraints, methods based on integer programming, branch-and-bound and dynamic programming have been proposed in the literature $[51,52,66,67]$. It is worth remarking that exact mathematical methods can be used only with small size problems because the combinations of states in which the solution must be searched increase exponentially $[53,68]$. To overcome some of these limitations, a number of meta- heuristic and soft computing based approaches for maintenance have been developed [54-56,58-61,69].

Stated the specific features of the optimization problem described above, in this paper we have investigated the applicability of Genetic Optimization technique and Monte Carlo method. Genetic algorithms (GAs) are techniques based on natural genetic and evolution mechanisms which can be used to solve complicated optimization problems by means of iterative procedures which work with a population of candidate solutions [68]. In genetic optimization algorithms, candidate solutions must be encoded using a suitable representation (e.g., a numeric string) and fitness function must be formulated to assign a quality value to every solution produced. GAs first generate an initial population of candidate solutions randomly or by some other means. The population is then evolved by creating new solutions from those in the current population by using GA operators such as selection, crossover and mutation.

Monte Carlo methods (or Monte Carlo experiments) are a class of computational algorithms that rely on repeated random sampling to compute results. These computational methods tend to be used when it is infeasible to find an exact result with a deterministic algorithm. Monte Carlo methods are especially useful for simulating phenomena with significant uncertainty in inputs. When Monte Carlo simulations have been applied in space exploration and oil exploration, their predictions of failures, cost overruns and schedule overruns are routinely better than human intuition or alternative soft computing methods [70-76].

The two methods have been applied to solve the described optimization problem and results pointed out positive and negative aspects. Genetic Algorithm showed high computational time to converge to a solution that satisfy the boolean constraints. Thus, GAs resulted very slow so that only computational experiments with a very limited number of generating units and horizon time could be simulated. Conversely, the Monte Carlo Method elaborated a large number of possible solutions. Each solution represents a possible maintenance scheduling of the wind power plants that satisfy the boolean constraints. Then the objective function is evaluated for each solution in order to determine the better one, that corresponds to the best maintenance scheduling. Monte Carlo method resulted very fast even in real world scenarios. Thus, we conclude that the Monte Carlo method is more suitable to solve the profit based maintenance problem discussed in this paper.

\subsection{The Proposed Monte Carlo Optimization Algorithm}

The proposed Monte Carlo method for solving the O\&M scheduling is not the standard Monte Carlo approach but a smarter version that is able to take into account the nature of the proposed optimization problem.

The standard Monte Carlo algorithm is formulated as described in Algorithm 1. A random realization of the matrix $\beta \in \mathbb{B}^{n U \times T}$ must be generated by random assigning to $\beta_{i U, t}$ the values 0 or 1. Then if all the constraints of the optimization problem over $\beta$ are satisfied the objective function is computed for this realization of $\beta$. This process is repeated $n_{M C}$ times and at the end the realization $\beta^{*}$ with the maximum value of the discounted profit is selected.

This approach becomes unreliable as soon as the number of constraints and variable increases. In particular with this standard approach only solutions with a very limited number of generating units and horizon time are found. 


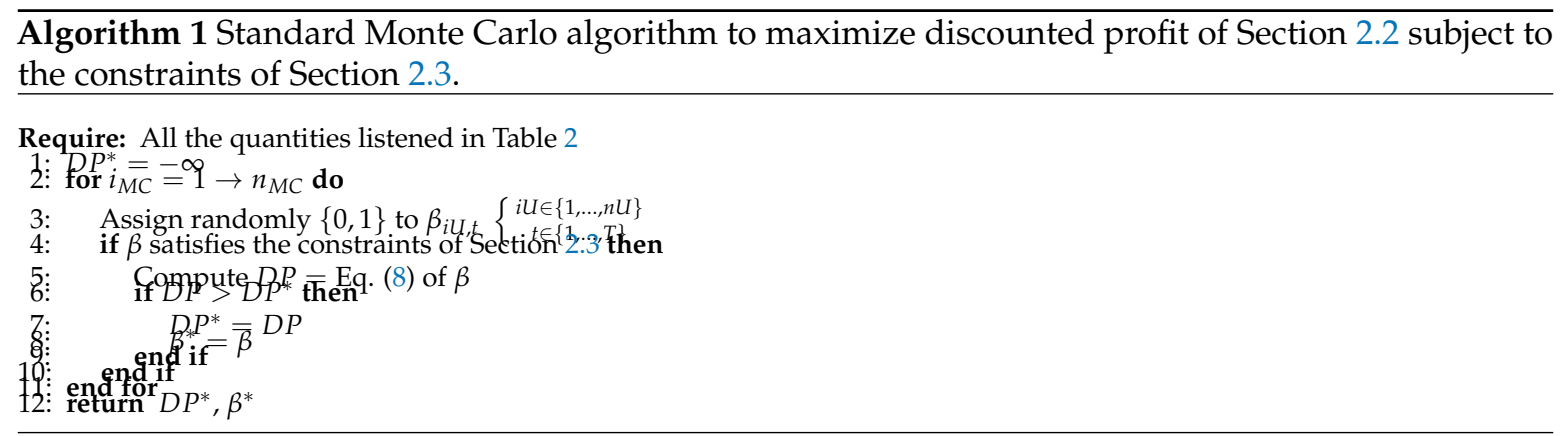

For this reason, a new algorithm with a new generation method of possible realizations of $\beta \in \mathbb{B}^{n U \times T}$ has been developed.

In particular this algorithm is able to generate with a Monte Carlo technique all the possible $\beta$ that satisfy the constraints of Section 2.3.

The proposed algorithm is logically divided in two parts. The first part generates all the possible $\beta$ that satisfy the constraints of Section 2.3 (see Algorithm 3) while the second part (see Algorithm 2) exploits the first one in order to find the $\beta^{*}$.

It is not possible to check all the solutions to the problem since the solutions space is too large, but the larger is $n_{M C}$ the more the solution chosen is the one with the maximum discounted profit (see Section 2.2).
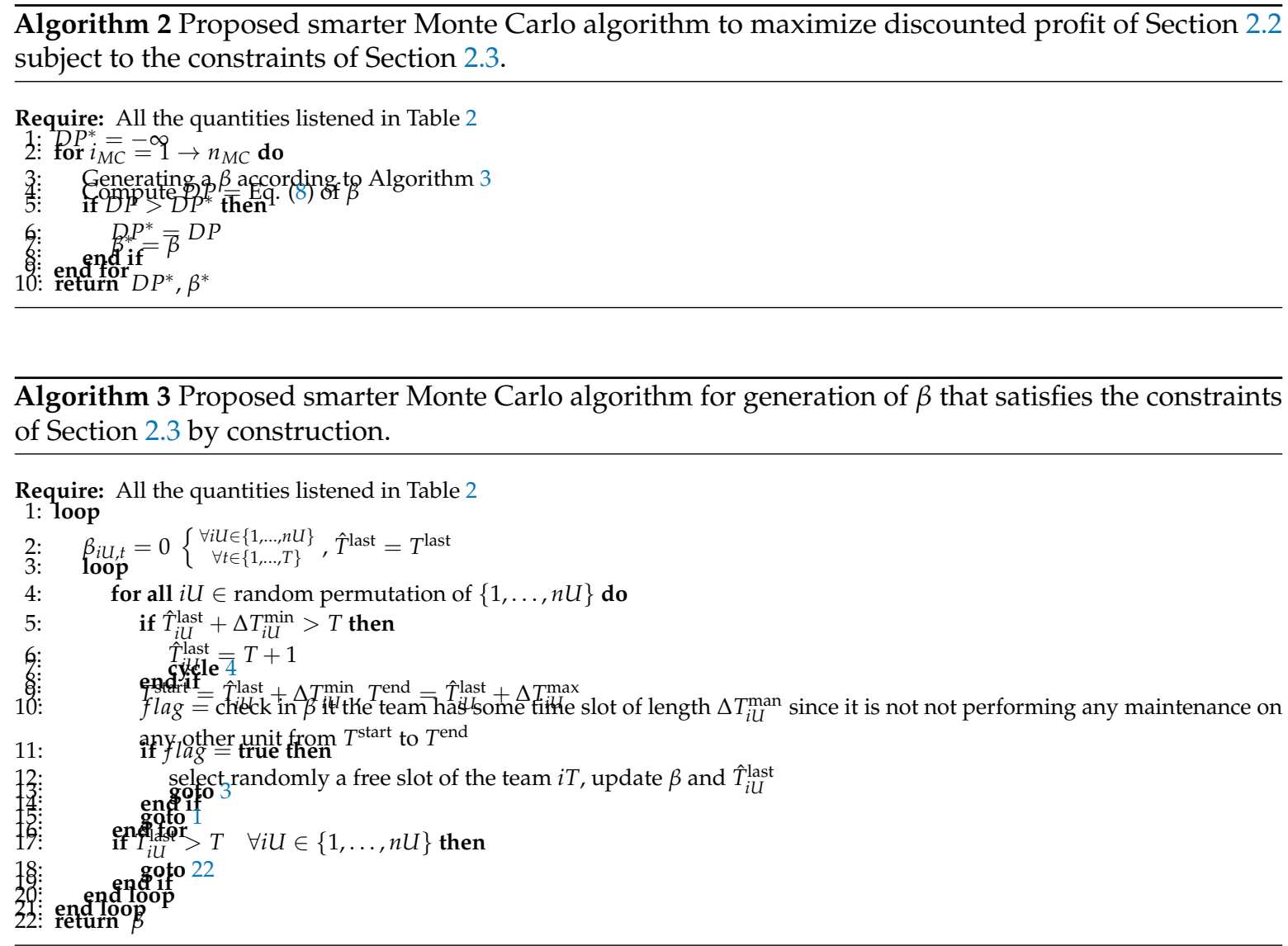

The idea behind Algorithm 3 is to built a maintenance scheduling $\beta$ starting from the constraints. This allows one to dramatically reduce the solution space and focus only on the space of the feasible maintenance scheduling. This solution allows us to perform simulations with a huge number of generating units. 
Finally, it is worth noting that in Algorithm 3 many random selections and permutations are present. All these random selections allow us to state that the proposed algorithm is able to explore all the solutions space if $n_{M C} \rightarrow \infty$. Note also that Algorithm 2 is completely parallelizable since the same code can run on different machines with a different seed for the random generator. Then the best solution between the ones that each machine has found can be selected.

\section{Computational Experiments}

The profit-based O\&M scheduling problem has been implemented in C programming language and its applicability have been tested on different computational environments. The objective of the simulations is the design of a maintenance schedule for a long-term horizon of about two years, i.e., $T=720$.

The time unit of the computational experiments is the day. For the sake of simplicity, the results of simulations performed with 13 sites $(S=13)$, with a number of power plants ranging from 3 to 7 in each site, are discussed.

Each power plant $i U$ has a minimum $\Delta T_{i U}^{\min }$ chosen in the range 3-12 and a maximum $\Delta T_{i U}^{\max }$ chosen between 150 and 298 for the time period between two consecutive operational maintenances.

Regarding the cost of the maintenance $C^{M}$, in the simulation it is fixed equal to 2 . This means that even if in the real world some parts must be ordered from a central warehouse and some complicated maintenances may require special equipments which must be hired from service suppliers, in the simulation, for the sake of simplicity, the necessary spare part or special equipment are considered always available. Moreover, the maintenance can be done with any weather condition.

Regarding the logistic $\operatorname{cost} C^{L}$, in the simulation a single team able to execute only one maintenance per time unit, and finish the maintenance before moving to the location of the next maintenance, is considered. Travelling from one site to another one takes a given amount of travel time, whereas moving from one generating unit to another one within the same site is negligible. The $C^{L} \operatorname{cost}$ is proportional to the distance between the sites and in the case of two power plants belonging to the same site the logistic cost is equal to zero. Thus, in the presented simulation the logistic cost ranges between 0 and 13 .

For the sake of compactness, all the parameters' values employed in the simulations have been summarized in Table 3.

Table 3. Parameters values used in the computational experiments

\begin{tabular}{clc}
\hline Symbol & Description & Value \\
\hline$S$ & Number of sites & 13 \\
$G$ & Number of generating units for site & $3-7$ \\
$T$ & Number of the time periods (planning horizon). & 720 \\
$C^{M}$ & maintenance intervention cost & 2 \\
$C^{L}$ & logistic costs matrix & $0-13$ \\
$\Delta T_{i U}^{\mathrm{kmin}}$ & minimum period of working time of unit $i U$ & $3-12$ \\
$\Delta T_{i U}^{\mathrm{kmax}}$ & maximum period of working time of unit $i U$ & $150-298$ \\
$\Delta T^{\operatorname{man}}$ & duration of maintenance for unit $i U$ & 2 \\
$r$ & discount factor & 0.993 \\
\hline
\end{tabular}

The schedule is updated every week or after a maintenance or in case of power plant failure.

In the simulations, all the generating units are subjected to the same energy price $P_{t}$, taken from the historical time series of the Italian National Single Price (PUN) from the 17-th of December 2012 to the 16-th December 2014. It is worth noting that for the sake of simplicity we use the energy price instead of forecast energy price $P_{t}$ in order to focalize the attention on the maintenance scheduling.

Figure 1 shows the energy price time series. 


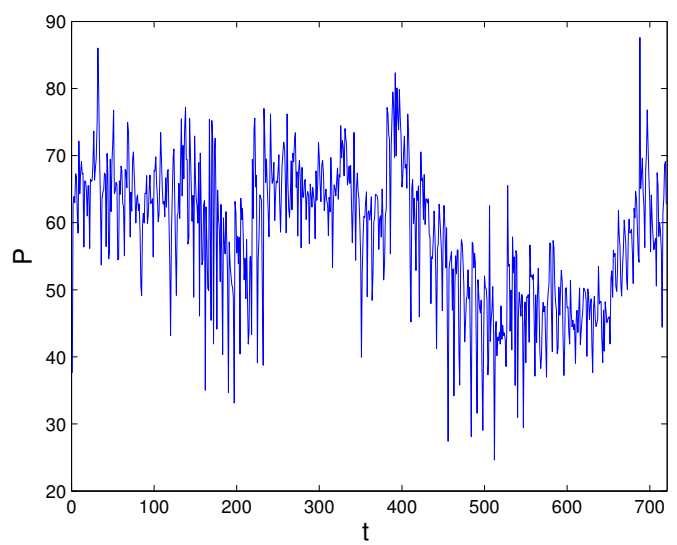

Figure 1. Italian National Single Price (PUN) from the 17-th of December 2012 to the 16-th December 2014

The expected production capacity $Q_{t, i} u$ depends on the forecasted weather condition (the wind speed) at time $t$ and on the technical characteristics of the generating unit $i U$. The expected production capacity series takes into account that in the short period the data are more reliable with respect to the long period. Figure 2 shows the expected production quantity for the first power plant.

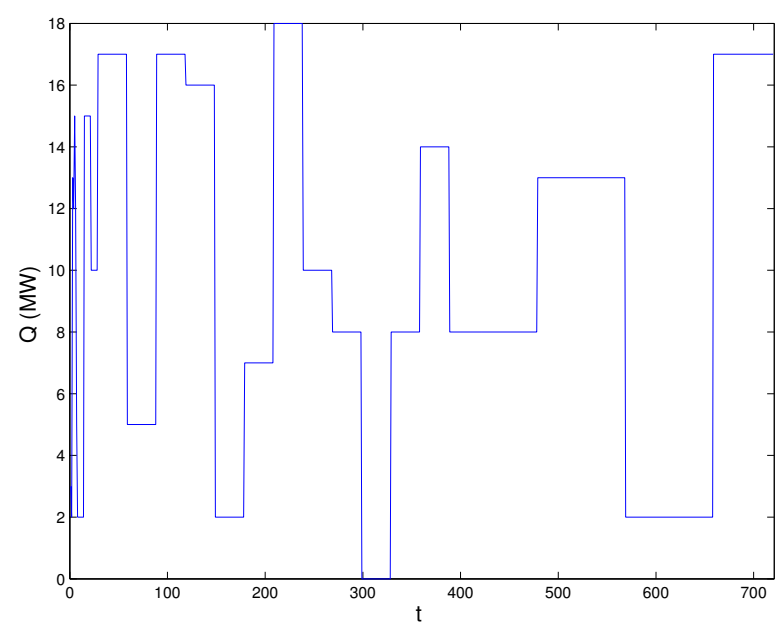

Figure 2. Expected production quantity in MW based on forecasting weather condition for the first power plant

The discount factor $r$ is evaluated according to:

$$
r=\sqrt[365]{r_{a}}
$$

where $r_{a}$ is a fixed annual discount factor equal to 0.1 . Thus the profit at one year ahead weights $1 / 10$ of tomorrow profit.

Figure 3 shows the optimal solution of the problem described in Section 2 in the case of $N=13$ sites and 63 generating units for two year ahead. 


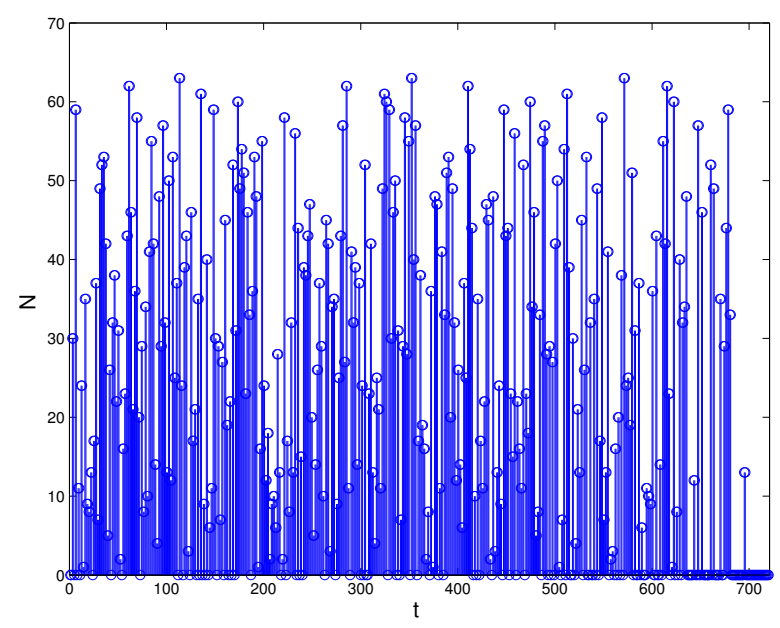

Figure 3. Optimal O\&M scheduling.

The objective has been to find the maintenance schedule that maximizes the discounted profit taking into account market and weather opportunities. This non-linear integer programming problem results extremely difficult to be solved for the boolean constraints. Moreover, the computational experiment has been run on a 64 core high performance workstation and Figure 3 shows the optimal sequence of starting maintenance time for the power plants portfolio.

\section{Conclusion}

The increasing importance of energy markets together with the foreseen reduction in incentive schemes for renewable energy require to extend the classic maintenance decision process and to consider also market and weather information. In this paper, starting from the classical maintenance theory, an O\&M strategy that incorporates forecasted market prices and weather conditions, reducing the overall maintenance cost and improving the expected profit of the systems, is presented. In particular, the proposed maintenance scheduling takes into account not only production opportunities but also market opportunities. For a given set of generation plants, the maintenance is performed in order to ensure the most profitable conditions in terms of energy prices and wind environment, rather than minimizing only maintenance costs. The theoretical and computational aspect employed for the design of the maintenance strategies that maximize profits have been presented and discussed. The maintenance schedule of the discounted cumulative profit of a wind generation portfolio in a fixed-time horizon (e.g. one years ahead) and subject to the technologically-derived maintenance time constraints has been optimized. In order to evaluate impacts of the location of warehouses, logistics costs have been also considered, assuming the Italian energy market as reference context for the sake of its peculiarity and availability of market and weather data (i.e., wind power plants are distributed in different market zones and receive a zonal price). Results pointed out that a more complete scheduling for a given set of wind power plants is achieved taking into account market and weather opportunities in the design of the maintenance strategy. Moreover, a new smarter nonlinear optimization algorithm able to maximize discounted profit has been developed, and will be used in the further developments (for example in the case of different type of maintenance, several maintenance teams, and different zonal prices).

Acknowledgments: This work has been partially supported by the University of Genoa.

\section{References}

1. Müsgens, F. Quantifying market power in the german wholesale electricity market using dynamic multi-regional dispatch model. The Journal of Industrial Economics 2006, 54, 471-498.

2. Kirschen, D.; Strbac, G. Fundamentals of power system economics; Wiley Online Library, 2004. 
3. Pastore, S.; Ponta, L.; Cincotti, S. Heterogeneous information-based artificial stock market. New Journal of Physics 2010, 12, 053035.

4. Ponta, L.; Raberto, M.; Cincotti, S. A multi-assets artificial stock market with zero-intelligence traders. Europhysics Letters 2011, 93, 28002.

5. Ponta, L.; Pastore, S.; Cincotti, S. Information-based multi-assets artificial stock market with heterogeneous agents. Nonlinear Analysis: Real World Applications 2011, 12, 1235.

6. Ponta, L.; Scalas, E.; Raberto, M.; Cincotti, S. Statistical analysis and agent-based microstructure modeling of high-frequency financial trading. IEEE Journal of Selected Topics in Signal Processing 2012, 6, 381-387.

7. Cincotti, S.; Gallo, G. GAPEX: An agent-based framework for power exchange modeling and simulation. International Conference on Agents and Artificial Intelligence, 2012, pp. 33-43.

8. Rastegar, M.A.; Guerci, E.; Cincotti, S. Agent-based model of the Italian wholesale electricity market. International Conference on the European Energy Market, 2009, pp. 1-7.

9. Guerci, E.; Ivaldi, S.; Cincotti, S. Learning agents in an artificial power exchange: Tacit collusion, market power and efficiency of two double-auction mechanisms. Computational Economics 2008, 32, 73-98.

10. Guerci, E.; Rastegar, M.A.; Cincotti, S.; Delfino, F.; Procopio, R.; Ruga, M. Supply-side gaming on electricity markets with physical constrained transmission network. International Conference on European Electricity Market, 2008, pp. 1-6.

11. Guerci, E.; Ivaldi, S.; Raberto, M.; Cincotti, S. Learning oligopolistic competition in electricity auctions. Computational Intelligence 2007, 23, 197-220.

12. Cincotti, S.; Gallo, G.; Ponta, L.; Raberto, M. Modeling and forecasting of electricity spot-prices: Computational intelligence vs classical econometrics. AI Communications 2014, 27, 301-314.

13. Fried, L.; Sawyer, S.; Shukla, S.; Qiao, L. Global wind report-Annual market update. Global Wind Energy Council 2012.

14. Zhang, P. Small Wind World Report 2012. World Wind Energy Association 2012.

15. Sawin, J.L. Renewables 2012: Global status report; REN21 Secretariat, Paris, France, 2012.

16. Kim, J.H.; Powell, W.B. Optimal Energy Commitments with Storage and Intermittent Supply. Operations Research 2011, 59, 1347-1360.

17. Cho, D.; Parlar, M. A Survey Of Maintenance Models For Multiunit Systems. European Journal Of Operational Research 1991, 51, 1-23.

18. Huiskonen, J. Maintenance spare parts logistics: Special characteristics and strategic choices. International journal of production economics 2001, 71, 125-133.

19. Buyukkaramikli, N.C.; van Ooijen, H.P.G.; Bertrand, J.W.M. Integrating inventory control and capacity management at a maintenance service provider. Annals Of Operations Research 2015, 231, 185-206.

20. Iung, B.; Levrat, E.; Thomas, E. Odds algorithm-based opportunistic maintenance task execution for preserving product conditions. CIRP Annals-Manufacturing Technology 2007, 56, 13-16.

21. Fan, J.; Griffin, C. Optimal digital product maintenance with a continuous revenue stream. Operations Research Letters 2017, 45, 282-288.

22. Budai, G.; Dekker, R.; Nicolai, R.P. Maintenance and production: a review of planning models. Complex System Maintenance Handbook, 2008, pp. 321-344.

23. Perron, L. Planning and scheduling teams of skilled workers. Journal of Intelligent Manufacturing 2010, 21, 155-164.

24. Kaihara, T.; Fujii, N.; Tsujibe, A.; Nonaka, Y. Proactive maintenance scheduling in a re-entrant flow shop using Lagrangian decomposition coordination method. CIRP Annals-Manufacturing Technology 2010, $59,453-456$.

25. Derigent, W.; Thomas, W.; Levrat, E.; Iung, B. Opportunistic maintenance based on fuzzy modelling of component proximity. CIRP Annals-Manufacturing Technology 2009, 58, $29-32$.

26. Davenport, A. Integrated maintenance scheduling for semiconductor manufacturing. Integration of AI and OR Techniques in Constraint Programming for Combinatorial Optimization Problems, 2010, pp. 92-96.

27. De Boer, R.; Schutten, J.; Zijm, W. A decision support system for ship maintenance capacity planning. CIRP Annals-Manufacturing Technology 1997, 46, 391-396.

28. Takata, S.; Kirnura, F.; Van Houten, F.; Westkamper, E.; Shpitalni, M.; Ceglarek, D.; Lee, J. Maintenance: changing role in life cycle management. CIRP Annals-Manufacturing Technology 2004, 53, 643-655. 
29. Wang, W. A simulation-based multivariate Bayesian control chart for real time condition-based maintenance of complex systems. European Journal of Operational Research 2012, 218, 726 - 734.

30. Joo, S.J. Scheduling preventive maintenance for modular designed components: A dynamic approach. European Journal of Operational Research 2009, 192, 512 - 520.

31. Kim, M.J.; Makis, V. Joint Optimization of Sampling and Control of Partially Observable Failing Systems. Operations Research 2013, 61, 777-790.

32. Besbes, O.; Gur, Y.; Zeevi, A. Non-Stationary Stochastic Optimization. Operations Research 2015, $63,1227-1244$.

33. Tsao, Y.C. A piecewise nonlinear optimization for a production-inventory model under maintenance, variable setup costs, and trade credits. Annals Of Operations Research 2015, 233, 465-481.

34. Vespucci, M.T.; Maggioni, F.; Bertocchi, M.I.; Innorta, M. A stochastic model for the daily coordination of pumped storage hydro plants and wind power plants. Annals of operations research 2012, 193, 91-105.

35. Dogramaci, A.; Fraiman, N. Replacement decisions with maintenance under uncertainty: An imbedded optimal control model. OPERATIONS RESEARCH 2004, 52, 785-794.

36. McKone, K.; Schroeder, R.; Cua, K. The impact of total productive maintenance practices on manufacturing performance. Journal Of Operations Management 2001, 19, 39-58.

37. Sousa, R.; Voss, C.A. Contingency research in operations management practices. Journal Of Operations Management 2008, 26, 697-713.

38. Batun, S.; Maillart, L.M. Reassessing Tradeoffs Inherent to Simultaneous Maintenance and Production Planning. Production And Operations Management 2012, 21, 396-403.

39. Ambuhl, S.; Sorensen, J.D. Sensitivity of Risk-Based Maintenance Planning of Offshore Wind Turbine Farms. Energies 2017, 10.

40. Nilsson, J.; Bertling, U. Maintenance management of wind power systems using condition monitoring systems. IEEE Power Engineering Society General Meeting, 2007, pp. 1-8.

41. Nielsen, J.J.; Sørensen, J.D. On risk-based operation and maintenance of offshore wind turbine components. Reliability Engineering \& System Safety 2011, 96, 218-229.

42. Amirat, Y.; Benbouzid, M.E.H.; Al-Ahmar, E.; Bensaker, B.; Turri, S. A brief status on condition monitoring and fault diagnosis in wind energy conversion systems. Renewable and sustainable energy reviews 2009, 13, 2629-2636.

43. Swanson, L. Linking maintenance strategies to performance. International journal of production economics 2001, 70, 237-244.

44. Panagiotidou, S.; Tagaras, G. Statistical Process Control and Condition-Based Maintenance: A Meaningful Relationship through Data Sharing. Production And Operations Management 2010, 19, 156-171.

45. Mazidi, P.; Tohidi, Y.; Sanz-Bobi, M.A. Strategic Maintenance Scheduling of an Offshore Wind Farm in a Deregulated Power System. Energies 2017, 10.

46. Kovács, A.; Erdős, G.; Viharos, Z.J.; Monostori, L. A system for the detailed scheduling of wind farm maintenance. CIRP Annals-Manufacturing Technology 2011, 60, 497-501.

47. Gopalakrishnan, M.; Ahire, S.; Miller, D. Maximizing the effectiveness of a preventive maintenance system: An adaptive modeling approach. Management Science 1997, 43, 827-840.

48. Cha, J.H.; Finkelstein, M. Stochastic analysis of preventive maintenance in heterogeneous populations. Operations Research Letters 2012, 40, 416-421.

49. Mukerji, R.; Merrill, H.M.; Erickson, B.W.; Parker, J.H.; Friedman, R.E. Power plant maintenance scheduling: optimizing economics and reliability. Power Systems, IEEE Transactions on 1991, 6, 476-483.

50. Endrenyi, J.; Aboresheid, S.; Allan, R.N.; Anders, G.J.; Asgarpoor, S.; Billinton, R.; Chowdhury, N.; Dialynas, E.N.; Fipper, M.; Fletcher, R. The present status of maintenance strategies and the impact of maintenance on reliability. Power Systems, IEEE Transactions on 2001, 16, 638-646.

51. Marwali, M.K.C.; Shahidehpour, S.M. A probabilistic approach to generation maintenance scheduler with network constraints. International Journal of Electrical Power \& Energy Systems 1999, 21, 533-545.

52. El-Sharkh, M.; El-Keib, A. Maintenance scheduling of generation and transmission systems using fuzzy evolutionary programming. IEEE Transactions on Power Systems 2003, 18, 862-866.

53. Yamayee, Z.; Sidenblad, K.; Yoshimura, M. A computationally efficient optimal maintenance scheduling method. IEEE Transactions on Power Apparatus and Systems 1983, 1, 330-338. 
54. Wang, Y.; Handschin, E. A new genetic algorithm for preventive unit maintenance scheduling of power systems. International Journal of Electrical Power \& Energy Systems 2000, 22, 343-348.

55. Baskar, S.; Subbaraj, P.; Rao, M.; Tamilselvi, S. Genetic algorithms solution to generator maintenance scheduling with modified genetic operators. IEE Proceedings Generation, Transmission and Distribution 2003, 150, 56-60.

56. Satoh, T.; Nara, K. Maintenance scheduling by using simulated annealing method [for power plants]. IEEE Transactions on Power Systems 1991, 6, 850-857.

57. Alrefaei, M.H.; Andradóttir, S. A simulated annealing algorithm with constant temperature for discrete stochastic optimization. Management science 1999, 45, 748-764.

58. El-Sharkh, M.Y.; El-Keib, A.A.; Choi, J.; Elagtal, I. Evolutionary programming-based maintenance scheduling of power generating units. International Conference on Probabilistic Methods Applied to Power Systems, 2004, pp. 141-144.

59. Burke, E.K.; Smith, A.J. Hybrid evolutionary techniques for the maintenance scheduling problem. IEEE Transactions on Power Systems 2000, 15, 122-128.

60. Kim, H.; Nara, K.; Gen, M. A method for maintenance scheduling using GA combined with SA. Computers $\mathcal{E}$ Industrial Engineering 1994, 27, 477-480.

61. Kim, H.; Hayashi, Y.; Nara, K. An algorithm for thermal unit maintenance scheduling through combined use of GA, SA and TS. IEEE Transactions on Power Systems 1997, 12, 329-335.

62. Ren, Y.; Suganthan, P.; Srikanth, N. A Novel Empirical Mode Decomposition With Support Vector Regression for Wind Speed Forecasting. IEEE transactions on neural networks and learning systems 2014.

63. Gallo, G.; Ponta, L.; Cincotti, S. Profit-based O\&M strategies for wind power plants. European Energy Market (EEM), 2012 9th International Conference on the. IEEE, 2012, pp. 1-7.

64. Torrielli, A.; Pia Repetto, M.; Solari, G. Long-term simulation of the mean wind speed. Journal of Wind Engineering and Industrial Aerodynamics 2011, 99, 1139-1150.

65. Bouzgou, H.; Benoudjit, N. Multiple architecture system for wind speed prediction. Applied Energy 2011, 88, 2463-2471.

66. Jiang, Y.; McCalley, J.D.; Van Voorhis, T. Risk-based resource optimization for transmission system maintenance. IEEE Transactions on Power Systems, 2006, 21, 1191-1200.

67. Huang, K.; Yang, H. Effective algorithm for handling constraints in generator maintenance scheduling. IEE Proceedings Generation, Transmission and Distribution 2002, 149, 274-282.

68. Miranda, V.; Srinivasan, D.; Proenca, L.M. Evolutionary computation in power systems. International Journal of Electrical Power E Energy Systems 1998, 20, 89-98.

69. Beasley, J.; Chu, P. A genetic algorithm for the set covering problem. European Journal Of Operational Research 1996, 94, 392-404.

70. Montes, G.M.; Martin, E.P.; Bayo, J.A.; Garcia, J.O. The applicability of computer simulation using Monte Carlo techniques in windfarm profitability analysis. Renewable and Sustainable Energy Reviews 2011, $15,4746-4755$.

71. Vehviläinen, L.; Keppo, J. Managing electricity market price risk. European Journal of Operational Research 2003, 145, 136-147.

72. Amelin, M.; Soder, L. On Monte Carlo simulation of electricity markets with uncertainties in precipitation and load forecasts. IEEE Porto Power Tech Proceedings, 2001, pp. 6-20.

73. Duenas, P.; Reneses, J.; Barquin, J. Dealing with multi-factor uncertainty in electricity markets by combining Monte Carlo simulation with spatial interpolation techniques. IET generation, transmission $\mathcal{E}$ distribution 2011, 5, 323-331.

74. Dahlgren, R.; Liu, C.C.; Lawarree, J. Using market simulation to manage price risk in a centrally cleared market. IEEE Power Engineering Society Summer Meeting, 1999, pp. 1261-1263.

75. Galloway, S.; Bell, G.; Burt, G.; McDonald, J.; Siewierski, T. Managing the risk of trading wind energy in a competitive market. IEE Proceedings Generation, Transmission and Distribution, 2006, pp. 106-114.

76. Jahangirian, M.; Eldabi, T.; Naseer, A.; Stergioulas, L.K.; Young, T. Simulation in manufacturing and business: A review. European Journal Of Operational Research 2010, 203, 1-13. 